\title{
Central pontine myelinolysis in association with Hodgkin's lymphoma
}

\author{
Louis A. LoIzou* \\ B.Sc., Ph.D., M.R.C.P.(U.K.) \\ JAN RoKOS $\dagger$ \\ M.D.
}

*Department of Neurology, Queen Elizabeth Hospital, Edgbaston, Birmingham, and $\dagger$ Department of Pathology

(Neuropathology), University of Birmingham

\begin{abstract}
Summary
Central pontine myelinolysis was found histologically in a young man who died with Hodgkin's lymphoma. Clinically he had developed a progressive peripheral sensory deficit, ataxia, quadriparesis, dysarthria, incontinence and drowsiness. This is the fifth case reported in the British literature. The pathogenesis and aetiology of this primary demyelinating disease are considered.
\end{abstract}

\section{Introduction}

Central pontine myelinolysis (CPM) was first described in 1959 by Adams, Victor and Mancall as an area of non-inflammatory demyelination affecting the central part of the basis pontis, with relative sparing of the nerve cell bodies and axons, little or no astrocytic reaction, loss of oligodendrocytes and normal blood vessels. In 2 of their 4 patients, who were malnourished chronic alcoholics, the lesion had manifested itself clinically by a pseudobulbar palsy and quadriplegia.

This distinct pathological process always develops in association with other conditions, notably alcoholism, malnutrition and electrolyte disturbances (Goebel and Herman-Ben Zur, 1976; Messert et al., 1979; Wright, Laureno and Victor, 1979). It may be associated with similar demyelinating lesions elsewhere in the brain (Tomlinson, Pierides and Bradley, 1976; Wright et al., 1979), Wernicke's encephalopathy (Goebel and HermanBen Zur, 1976) and Marchiafava-Bignami disease (Ghatak, Hadfield and Rosenblum, 1978). A few cases have been described, in whom the diagnosis was made on clinical grounds and confirmed histologically (Paguirigan and Lefken, 1969; Wiederholt et al., 1977; Anderson et al., 1979; Messert et al., 1979). In most cases, however, the lesion is small and clinically silent so that diagnosis is only reached at post-mortem.

The authors describe a young man with Hodgkin's lymphoma, who developed a syndrome and a pathological process compatible with CPM. This is the fifth reported case in the British literature (Adams, 1962; Tomlinson et al., 1976).

\section{Case report}

A 28-year-old man presented in March 1977 witb cervical lymph nodes infiltrated by Hodgkin's tissư of mixed cellularity. The spleen was similarls affected, but there were no other abnormalities. He was treated with upper mantle extended radios therapy using ${ }^{60} \mathrm{Co}$. He remained well till May $197 \%$ when he complained of loss of appetite and weight night sweats and dyspnoea. He was found toobe anaemic $(\mathrm{Hb} 8 \mathrm{~g} / \mathrm{dl})$ and was transfused packed cells.

In June 1978 he developed numbness and cutaneơu sensory loss in the feet. The haemoglobin was $9 \cdot \overline{\mathscr{Q}}$ $\mathrm{g} / \mathrm{dl}$, the bone marrow was infiltrated by Hodgkin tissue, electrolytes and liver function tests were normal; he was transfused packed cells.

In July 1978 his neurological disability had pro gressed, with numbness up to the thighs, develop ment of weakness and ataxia in all 4 limbs especially the legs, so that he could not walk ung aided, slurring of speech and finally urinary incontinence. He had continued to feel ill with pyrexia and night sweats. Examination showed normal $\mathbf{B P}_{\odot}$. pallor, pyrexia and right hypochondrial tenderness? Neurological examination showed mild confusion psychomotor retardation and dysarthria; the fund were normal. There was bilateral impairment of lateral gaze but no nystagmus, mild bilateral faciał. weakness and profound sensorineural deafness bî laterally. In the arms there was moderate pyramidal weakness with bilateral intention tremor mores pronounced on the left side and some postural drif of the outstretched arms. In the legs there was profound spastic ataxic paraparesis. All reflexef were exaggerated except the right supinator whic $\$$ was absent. The plantar responses were extensor and superficial abdominal reflexes absent. Pain sensatio and vibration sense were impaired below the groins and there was loss of joint position sense in the toesed 
He exhibited truncal ataxia on sitting up in bed and was incontinent of urine. The clinical suspicion was of metastatic disease in the brain stem with fourth ventricular outflow obstruction leading to hydrocephalus; the depression of the right supinator reflex raised the possibility of a second lesion at cervical level.

Investigations showed anaemia, thrombocytopenia, serum sodium at $129 \mathrm{mmol} / \mathrm{l}$ and slightly elevated alkaline phosphatase at $22 \mathrm{KAu}$./dl. Plain radiographs of the cervical spine and skull were normal. Computerized tomography (CT) of the brain showed ventricular dilatation involving the third and lateral ventricles and a low density area in the basis of the mid-pons (Fig. 1). Cerebrospinal fluid examination was normal.

Treatment was commenced with procarbazine $150 \mathrm{mg}$ and dexamethasone $12 \mathrm{mg}$ orally daily, mustine hydrochloride and vinblastine $12 \mathrm{mg}$ i.v., on days one and 8 . He deteriorated slowly and died on the 20th day with bronchopneumonia and gastrointestinal haemorrhage through marrow suppression.

\section{Pathological findings}

Generalized Hodgkin's disease involving the cervical, para-aortic abdominal lymph nodes, liver and bone marrow was confirmed. Macroscopic examination of the brain showed diffuse cerebral

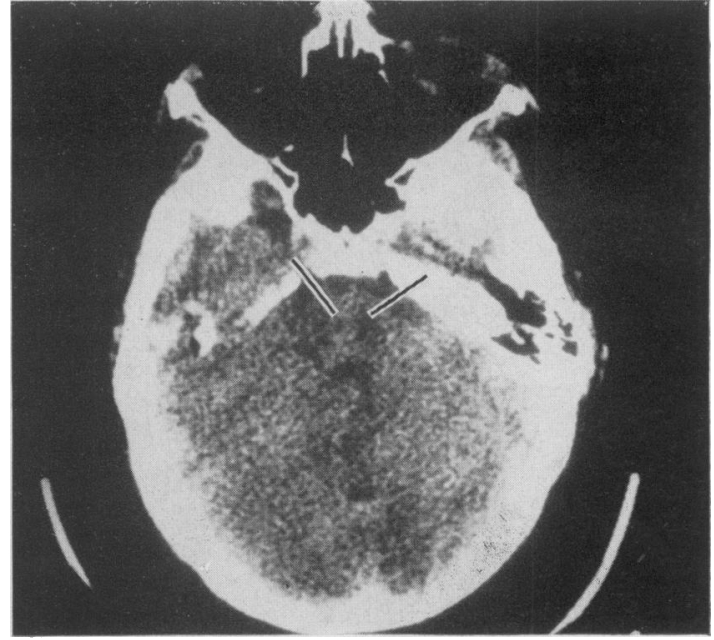

FIG. 1. CT scan at the level of the pons. Note the low density area in the centre of the pons (arrows).

oedema $(1825 \mathrm{~g})$. There was mild dilatation of the lateral ventricles due to subarachnoid fibrous adhesions. Microscopic examination of the cortex and basal ganglia was normal. Striking microscopic changes were found in the pons. At the level of the trigeminal nerves there was a marked symmetrical

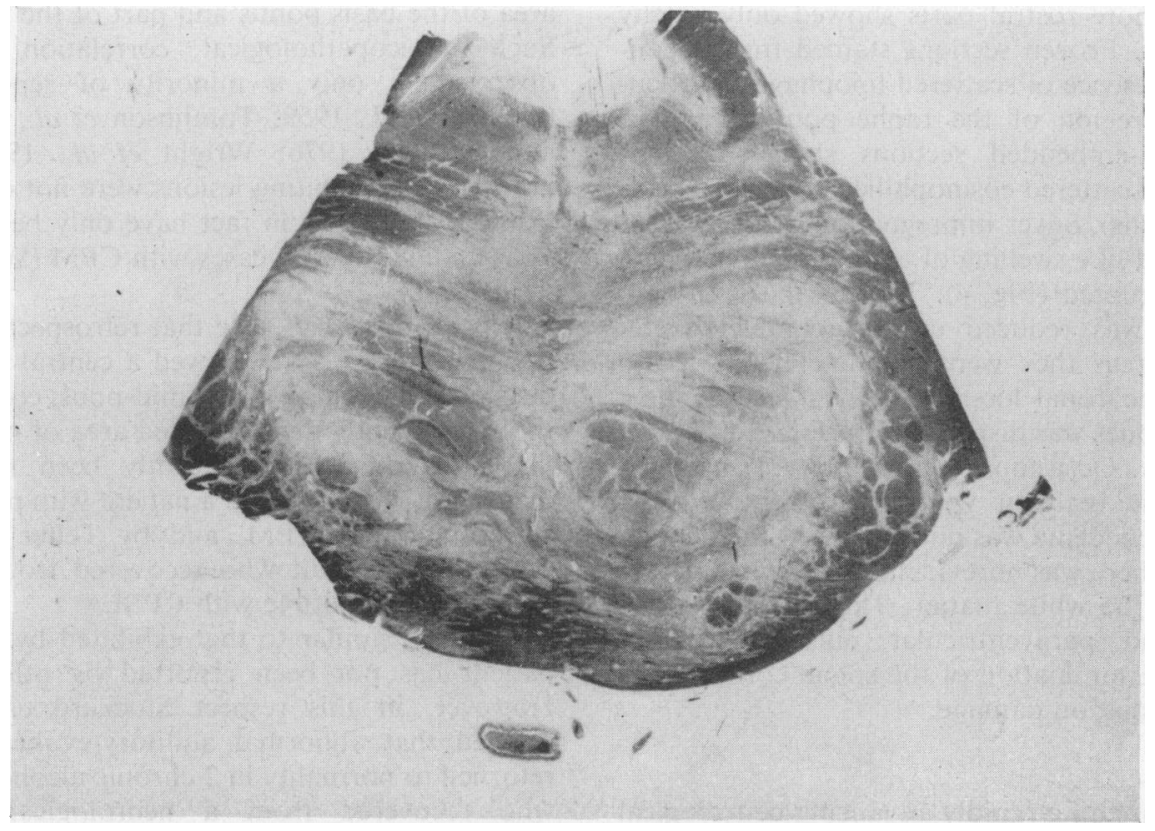

Fig. 2. Pons at the level of trigeminal nerves. Symmetrical myelin pallor with preservation of myelin at the periphery. Luxol fast blue (cresyl fast violet, $\times 3 \cdot 5$ ). 


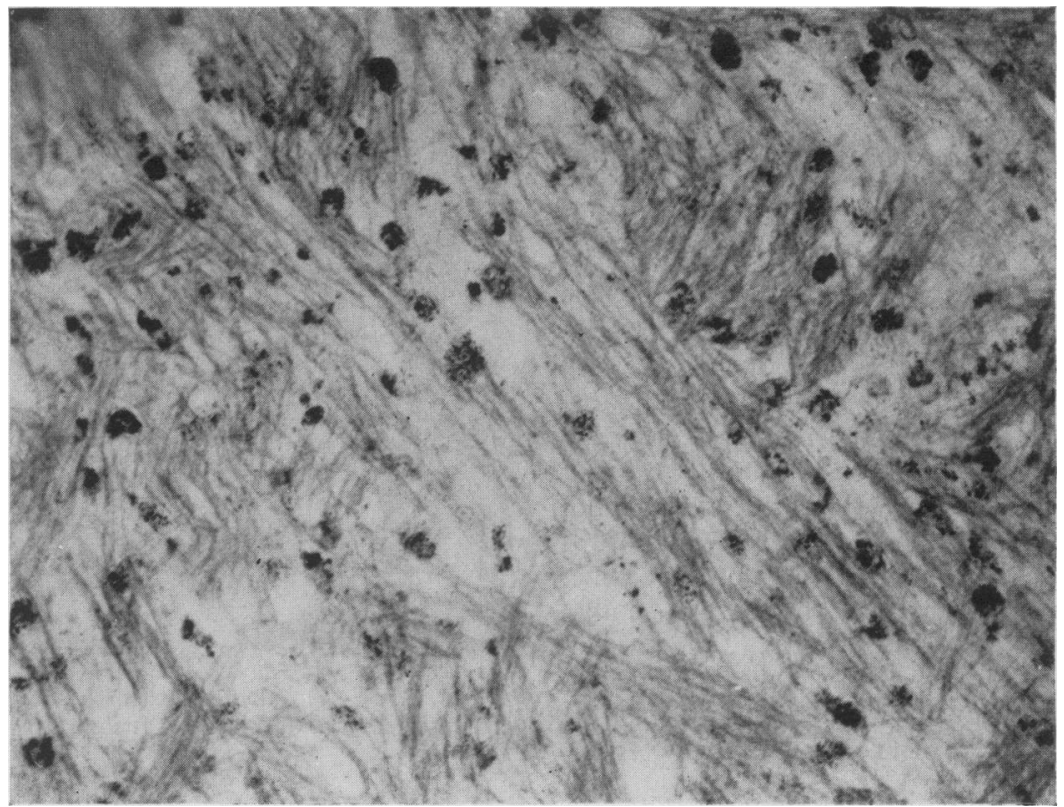

FIG. 3. Collections of lipophages in demyelinated part of the pons. Frozen section (Sudan IV, $\times 125)$.

myelin pallor of the central part of the pons, partly extending into the tegmentum (Fig. 2). Both longitudinal and transverse fibres were affected. The white matter at the periphery of the pons was preserved, but more rostral parts showed only patchy myelin pallor. Frozen sections stained for fat confirmed the presence of scattered lipophages, particularly in the region of the raphe pontis (Fig. 3). Paraffin wax-embedded sections showed spongy oedema with scattered eosinophilic axonal spheroids (retraction balls). Silver impregnation demonstrated irregular bead-like swelling of axons, some of which appeared disrupted (Fig. 4). The number of oligodendrocytes was reduced and in completely demyelinated areas they were absent. There was no evidence of neuronal loss. Nissl substance in most pontine neurones was dispersed or preserved only on the periphery. Occasional neurones were shrunken but astrocytic reaction was not present. Myelin pallor due to oedema was noted around the dentate nucleus but there was no evidence of demyelination elsewhere in the white matter. The medulla, hypothalamus and paraventricular nuclei were unremarkable. Examination of the spinal cord did not reveal any radiation damage.

\section{Discussion}

This patient had a rapidly advancing neurological disability with evidence of involvement of the corticospinal, corticobulbar and sphincter pathways as well as of the pontocerebellar connections, spinothalainic tracts and medial lemnisci. The progressive neư̄ं. logical deficit could be attributed to progression? the myelinolytic lesion, which involved an extensiveo area of the basis pontis and part of the tegmentum? Such clinicopathological correlation has beem observed in only a minority of reported cases (Adams et al., 1959; Tomlinson et al., 1976; Simas and Bradvik, 1976; Wright et al., 1979). Extra pontine demyelinating lesions were not encountered? in this patient and in fact have only been reportedo in a small number of cases with CPM (Wright et al. 3 . 1979).

It is of interest to note that retrospective examin ation of the CT scan showed a central area of lowo density in the region of the mid-pons, comparable to the subsequently demonstrated area of myelinolysis. Similar findings have recently been reported by Anderson et al. (1979) in a patient with post-mortem confirmation of CPM, and by Telfer and Millen (1979) in a patient who recovered from a clinical syndrome compatible with CPM.

Deafness similar to that exhibited by the present patient has not been reported by other authors? However, in this respect Stockard et al. (1976) showed that abnormal auditory-evoked responsesD returned to normality in 2 chronic alcoholic patients? who recovered from a neurological syndrome compatible with central pontine myelinolysis.

There are only 4 other documented cases of CPMP 


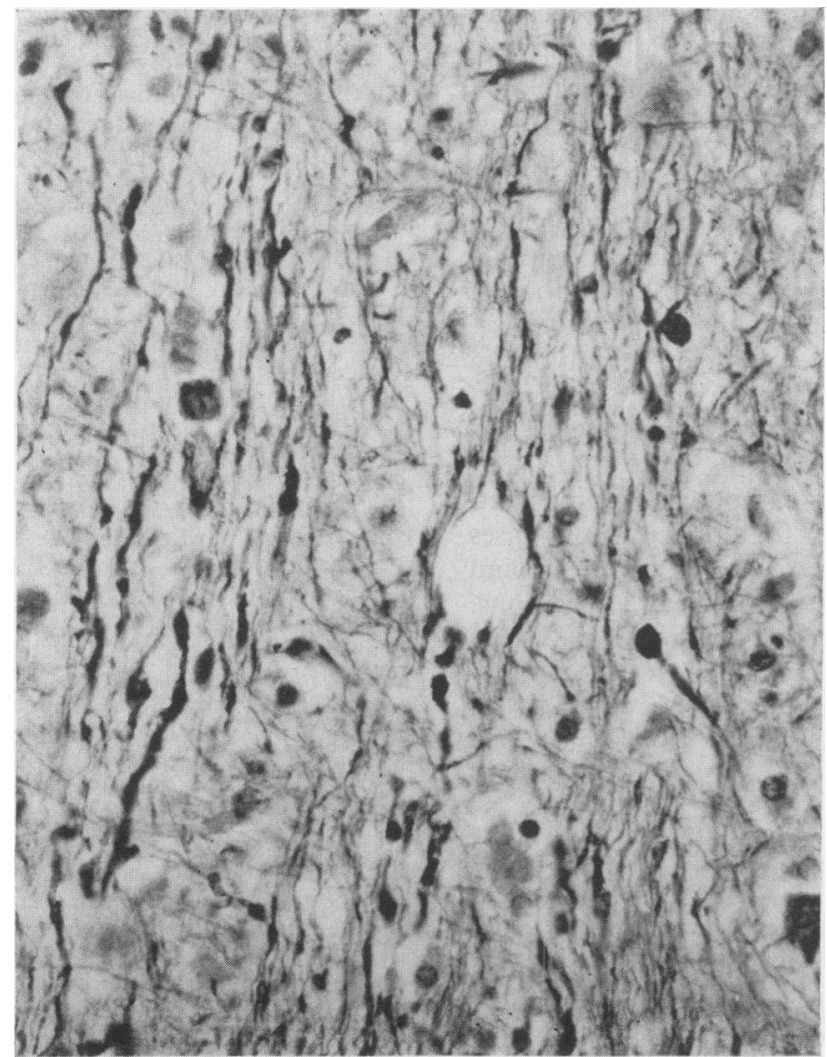

FIG. 4. Irregular axonal swelling (Glees Marsland's silver impregnation, $\times 303$ ).

in the English literature (Adams, 1962; Tomlinson et al., 1976) and a further illustrated case appears in Greenfield's Neuropathology (Oppenheimer, 1976). The explanation for this low incidence of CPM in Britain may be that the condition is indeed rare, or that it is not sufficiently recognized by clinicians and neuropathologists to be reported. The present authors would consider, however, the condition to be rare in view of the fact that this present case is the first one encountered in 2 neurological centres of the West Midlands in nearly 20 years.

Consideration of the aetiology of CPM in this patient reveals that certain common associations reported in the literature are not applicable. Infection did not occur, and chemotherapeutic agents were not administered until after the declaration of the neurological syndrome. Hypotensive episodes were not recorded at any time. Electrolyte disturbances which have been described from a large number of patients (Burcar, Norenberg and Yarnell, 1977) were not manifest in this patient at any time except for marginal hyponatraemia terminally.
Weight loss though present did not take the form of cachexia and malnutrition. Alcoholism and release of lipolytic enzymes (Vogel, 1978) simply did not exist. Although cerebral radiotherapy combined with chemotherapy has been reported to cause multi-focal necrotic lesions in the basis pontis (Breuer, Blank and Schoene, 1978) the histological appearance of these lesions is different from those of CPM; they show microvacuolization with marked myelin destruction, axonal breakdown and multiple axonal swellings. Thus, the authors are inclined to suggest that the development of CPM in their patient probably had a multifactorial basis, namely the underlying Hodgkin's lymphoma, infiltration of the liver and some form of nutritional deficiency.

This case is the third reported in association with Hodgkin's lymphoma. The first was reported by Valsamis, Peress and Wright (1971) from a child in whom the pontine lesion was small and asymptomatic; the second was reported by Wright et al. (1979) from a 9-year-old child. CPM has also occurred in association with leukaemia (Cadman 
and Rorke, 1969) and other neoplasms. In this respect it resembles progressive multifocal leucoencephalopathy, a well known complication of leukaemias and reticuloses, the aetiology of which is thought to be Papovavirus infection (Hildebrand, 1978). The available electronmicroscopic evidence, however, does not support a viral infective pathogenesis for CPM, nor indeed an immunologically based destruction of oligodendrocytes; rather it points to the possibility of a toxic-metabolic cause, with associated electrolyte changes, resulting in oedema of the myelin sheaths with subsequent rupture and destruction (Powers and McKeever, 1976).

Awareness of this clinico-pathological demyelinating disease may result in recognition of more cases and possibly elucidation of its pathogenesis and relationship to the various aetiological associations.

\section{Acknowledgments}

We would like to thank Mrs E. Simpson for preparation of the manuscript and Professor Walter Smith for helpful criticism.

\section{References}

Adams, R.D., Victor, M. \& Mancall, E.L. (1959) Central pontine myelinolysis. A hitherto undescribed disease occurring in alcoholic and malnourished patients. Archives of Neurology and Psychiatry. Chicago, 81, 154.

Adams, J.H. (1962) Central pontine myelinolysis. In: 4th International Congress of Neuropathology, Munich 1961 (Ed by Jacob H.), p. 303. George Thieme Verlag, Stuttgart.

Anderson, T.L., Moore, R.A., Grinnell, V.S. \& Itabashi, H.H. (1979) Computerized tomography in central pontine myelinolysis. Neurology. Minneapolis, 29, 1527.

Breuer, A.C., Blank, N.K. \& Schoene, W.C. (1978) Multifocal pontine lesions in cancer patients treated with chemotherapy and CNS radiotherapy. Cancer, 41, 2112.

BurCar, P.J., NorenberG, M.D. \& Yarnell, P.R. (1977) Hyponatremia and central pontine myelinolysis. Neurology. Minneapolis, 27, 223.
CAdman, T.E. \& RoRke, L.B. (1969) Central pontine mye- 气 linolysis in childhood and adolescence. Archives of Disease in Childhood, 44, 342.

Ghatak, N.R., Hadfield, M.G. \& Rosenblum, W.I. $c$ (1978) Association of central pontine myelinolysis and $\stackrel{\rightleftarrows}{\rightrightarrows}$ Marchiafava-Bignami disease. Neurology. Minneapolis, 28, 1295.

Goebel, H.H. \& Herman-Ben Zur, P. (1976) Central pontine myelinolysis. In: Handbook of Clinical Neurology, No. 28 을 (Ed by Vinken, P.J. \& Bruyn, G.W.), p. 285. North Holland Publishing Co., Amsterdam.

Hildebrand, J. (1978) Lesions of the Nervous System in $\varrho$ Cancer Patients (Ed by Staquet M.J.), p. 96. Raven Press, New York.

MesSert, B., OrRison, W.W., Hawkins, M.J. \& Quaglieri, CH.E. (1979) Central pontine myelinolysis. Neurology. Minneapolis, 29, 147.

OPPENHEIMER, D.R. (1976) Demyelinating diseases. In: ब Greenfield's Neuropathology (Eds Blackwood, W. \& Corsellis, J.), 3rd edn, p. 470. Edward Arnold, London.

Paguirigan, A. \& LefKen, E.B. (1969) Central pontine iv myelinolysis. Neurology. Minneapolis, 19, 1007.

Powers, J.M. \& MCKeEver, P.E. (1976) Central pontine के myelinolysis. An ultrastructural and elemental study. Journal of the Neurological Sciences, 29, 65.

Sima, A. \& BRADVIK, B. (1976) Central pontine myelinolysis. N Acta pathologica et microbiologica scandinavica, 84, 73 .

StOCKARD, J.J., Rossiter, V.S., Wiederholt, W.C. \& KOBAYASHI, R.M. (1976) Brain stem auditory-evoked responses in suspected central pontine myelinolysis. Archives of Neurology, 33, 726.

Telfer, R.B. \& Miller, E.M. (1979) Central pontine mye- linolysis following hyponatremia demonstrated by cons $\overrightarrow{0}$ puterized tomography. Annals of Neurology, 6, 455 .

Tomlinson, B.E., Pierides, A.M. \& Bradley, W.G. (197Central pontine myelinolysis. Two cases with associate electrolyte disturbance. Quarterly Journal of Medicine (New Series), 40, 373.

Valsamis, M.P., Peress, N.S. \& Wright, L.D (1971) Central pontine myelinolysis in childhood. Archives of Neurology, 25, 307.

VoGEL, S.F. (1978) Conundrum of central pontine myelinolysis. Pathology Annual, 13 (part I), 29.

Wiederholt, W.C., KobayaShi, R.M., Stockard, J.J. \& Rossiter, V.S. (1977) Central pontine myelinolysis. Archives of Neurology, 34, 220.

Wright, D.G., Laureno, R. \& Victor, M. (1979) Pontine and extrapontine myelinolysis. Brain, 102, 361 . 